\title{
Public Space and the Coevolution of Digital and Digitized Media
}

In the first section it is argued that digital media are characterized by a variable functional architecture. In the second section, it is argued that theories of replacement and convergence ought to be replaced by a theory of coevolution in order to understand how the Internet and mobile media are integrated in different societies. The third section discusses whether the influence of the old media in this coevolutionary process also implies that differences in the existing media systems will lead to different developments in the Internet.

\section{Digital media have a set of unique - first-ever - - properties}

Digital media provide an array of new features that are neglected in existing theories. Among those features, we find hypertext, multimodal communication and a register of new interactive formats. These features are rooted in the fundamental property of digital media: that the functional architecture of the medium, contrary to print and electronic media, can be modified, changed or suspended by means of individual messages sent in the very same medium. 'Tim Berners-Lee's publication of the www-protocols offers a prime example, as they were disseminated and quickly developed into standard software, thus providing a new public space in all nations throughout the world, whether requested or not. The open source development provides a wide range of examples; another set is provided by the shaping of the Internet through users' choices of features, functions and formats.

The functional architecture of computers and the digital media is born as variable. In this respect, they differ from all formerly known machines and media, which provides digital media with a unique adaptive potential. This variability is based on the principle of the 'universal' computer: the functional architecture can be defined in exactly the same textualized format as the content: as sequences of individually editable bits. Sequences that are used for the same purposes over and again may be replaced by physically implemented mechanical features (as automated invariant sequences) at the cost of the step-by-step variability. If so, you get a dedicated computer defined by a specialized purpose such as personal computers, with a wide range of purposes, game consoles, or mobile devices (the iPod and MP3 players, mobile DVD-devices, cell phones, BlackBerries, PDAs) in the one end of the scale, while digitized broadcast television belongs at the other end, as the dedication is directed to the maintenance of previously existing purposes and practices. The personal computer and the Internet belong somewhere in the middle, between the immobile and mobile digital media. These examples demonstrate that digitization does not tell anything about the implications of digitization on the grounds that digital media can be adapted to all sorts of old and new purposes. At the same time, it tells that the very same array of possible applications is what distinguishes digital media different from all formerly known media.

\section{Digital media are biased in their own manner} Digital media integrate both asynchronous and synchronous communications that were formerly distributed 
among different media. Speech and analogue electronic media are synchronous; writing and printing are asynchronous. Digital media are both. They integrate the storage capacities of print media with the communication speed of the electronic media. Contrary to the former electronic mass media, the Internet also provides a functional architecture based on symmetry between the communicating parts. Networked computers allow an indefinite array of new kinds of combinations including nearby synchronous formats such as chat, instant messaging, email, debate forums, weblogs, RSS feeds, podcasts, etc.

The integration of asynchronous and synchronous communication also forms a basis for radical transformations of the functioning of the public sphere - understood as those parts of public and private spaces used for public reasoning regarding public affairs possibly aimed at influencing these affairs. As the most basic transformation, the Internet implies a breakdown of all of the former media constraints for the synchronization of the citizens, whether readers, audiences, viewers or users. Content can be published, distributed and accessed around the clock, whether locally, regionally, nationally or transnationally; political (re-)action can be taken whenever a citizen or group wants to do so. Obviously, this does not mean that the public will not remain synchronized and maintain certain regularities, but it must do so deliberately without the support of the former media constraints. The synchronizing constraints of print and electronic mass media technologies, respectively, are now transformed into optional variables. ${ }^{2}$ New patterns and mediated platforms for public spheres will develop.

The synchronizing capacities of media are not a matter of frequency alone; this is also a matter of reach. Even if the print media have a global reach, they do not have the capacity to synchronize a globally distributed public audience because of the differing distribution time. Actually, they could not establish a synchronized nationwide public sphere before the advent of the telegraph, which provided the local newspapers with national and international news, and the rotary press, which made rapid and cheap mass-reproduction possible.

\section{Mediation expanded}

With the spread of the digital media, the whole frame of mediated communication is widened. Even if access to the Internet remains restricted to less than 20 percent of the world population and local and national usage is dominating compared to transnational use, the Internet: provides a new type of mediated space allowing individual access worldwide. The reach of this mediated space is further expanded by connections to a wide range of cell phone networks. Mediated public, semi-public and private space is available and accessible for any individual, group, company or institution; limited not by location, but by language, education, knowledge and culture. A variety of digitized and born-digital media are now embedded in daily life. One aspect relates to the use of digital media for performing actions at a distance, replacing face-to-face activities or phone/mail activities. You can visit a 'virtual' store instead of the 'real' store. Some of these processes may be best understood as new means of performing already-known activities, while others are better understood as new kinds and types of activities that were not possible without digital media. The distinction is blurred: the Internet favors the development of non-local, eventually transnational communities, but it would be a mistake to claim that such communities did not previously exist. It would also be mistaken, however, to claim that peer-to-peer communities, such as those formed around Napster, Gnutella, Kazaa or Myspace, would emerge without the Internet. At the same time, the Internet also favors local public spheres.

\section{Digitalmedia integrate both asynchronous and synehronous communications that were formerly distributed among different media."}

Again, the generic property separating digital media communities from other forms of mediated communities is that digital media communities are able to utilize the integration of the storage capacities of print media and the communication speed of electronic media. This is also the basis for the changes of scaling addressed by Sassen (2006).

\section{The media matrix reaches a new level of complexity} The transformation of local newspapers to media for a national public sphere depended on the telegraph and the rotary press. Together, they formed a coevolutionary 
media system, thus establishing one of the moments in which a new level of complexity in the societal matrix of media emerges. Such moments are rare, but significant. The printing press established such a moment in the history of writing; the same goes for the combination of printed newspapers and modem electronic mass media in the 2oth century and for the emergence of an increasing number of digital media, foremost the Internet and mobile media, in the late 20 th and early 21 st centuries. They also appear to occur more or less parallel in different countries, even if the media systems differ. This is why it is of relevance to distinguish between the matrix of media - the set of available media - and the media system - the specific way any given matrix is organized and exploited (cf. Hallin \& Mancini 2004). The historical perspective may help identify the crucial and general perspective in the present process of the integration of digital media taking place throughout the world, though the process is initiated by very different social dynamics, including different existing media systems.

\section{The overall flow of information in the world is changed in directions and scales."}

Today, digital media are added to the existing set of available media, thus providing a new and more complex matrix allowing an increased amount of options and a far-reaching expansion of mediated public space. The overall flow of information in the world is changed in directions and scales. A theory of digital media should therefore also include a theory regarding the emergence of new levels of complexity and a theory of interrelations between all of the available media. The decisive question is whether the field of study has shifted because of the emergence of new parameters (e.g. hypertext as an increase in the overall organizational complexity) that are not taken into account in previous theories.

As regards the level of complexity, there is both an increased number of media types and a stronger interrelationship between the media. All of the existing media are now on the Internet and print media are converting themselves into media houses. In addition to path dependency, which is a well-known relation between the old and new media, there are now also intensified simul- taneous cross-media interrelations and interferences, partly due to deliberate strategies and partly because of inspirational influence.

Digital media are characterized by a number of significant first-ever properties anchored in the variability of the textualized functional architecture. They are biased differently from all of the formerly known media, and they represent an expansion of both the public and private mediated spaces and contribute to the development of a new, more complex media matrix. A theory of digital media ought to be able to address all of the issues related to this. Let us consider the relationship to the old media.

\section{Available theories}

We can distinguish a series of the theories thus far:

a) Cyberspace theories suggesting the emergence of a new, separate universe beyond real life, a parallel 'Virtual community' (Rheingold 1993), a 'City of Bits' or 'E-topia' (Mitchell 1996, 1998) 'Being Digital' (Negroponte, 1995).

b) Theories of complete replacement (Mcluhan 1964; Boltz 1993; Negroponte 1995; Poster 1995; Nielsen 1998; Moravec 1998, 2000; Deibert 1997).

c) Theories of a new hegemonic superstructure (Castells 1996-1998).

d) Theories of convergence (indefinite number of references, Gordon 2003).

e) Theories of supplementation and/or enhancement (Thompson 1995; Dahlgren 2001; Born 2006).

e) Theories of evolution (Levinson 1997; Deibert 1997; Schulz 2004) and coevolution (suggested here).

Ad a) The notion of cyberspace as a new, autonomous and virtual space of its own - outside of real life - promoted in the 1990s, though not always as articulated theory - is unsuitable. People obviously use the Internet 
in ordinary life and we require theories capable of articulating the process of integration.

Ad b) Replacement theories come in varying degrees of radicalism. Most radical is probably Moravec (1998 \& 2000), arguing that computers (artificial intelligence) will outperform the human mind and bring the history of man as the dominant creature in nature to an end. The adherents of this theory do not discuss how digital media are integrated in culture - why should they?

Another set of radical replacement theories are formed around McLuhan's notion that electronic media bring with them the end of the Gutenberg Galaxy due to their auditory and visual capacities. While McLuhan included digital media in his notion of electronic media, others like Norbert Boltz (1993) draw a distinction but maintain the same implication concerning a transition to an audiovisual paradigm. Deibert (1997) also opposes print culture and digital culture, while Poster (1995) opposes (analogue) electronic culture and digital culture. According to these theories, the various media bring with them a new, dominating conceptual paradigm replacing former paradigms. Since the new conceptual framework is derived automatically from the new media, it follows - to be coherent - that the transition is considered to be a complete replacement. Contrary to this, it could be argued that digital media are textual media - based as they are on the binary alphabet - and hence represent an evolution of modern text-based culture into a wider scale, including the textualisation of audiovisual articulations (cf. Finnemann 1997).

A more modest variant is the idea of a complete technological takeover, articulated e.g. by Jakob Nielsen, the usability expert who predicted that the Internet would replace all 'legacy media' (magazines, books, newspapers, television) within a decade (Nielsen 1998). It is true that all of the older media can be digitized, but this does not mean that this will ever happen, whether in the near future or in a long-term perspective. There are strong cases against. A similar prediction in the 1980 s claiming the disappearance of printed text in the offices was obviously erroneous. Electronic text is now also used to produce a dramatically increased amount of printed texts, while the role of the printed text has shifted from the basic storage format to being print-just-in-time, in the appropriate number, on the appropriate location and in any appropriate physical form. We have not arrived at end of print, but rather at the end of 'out of print'. Newspapers, radio and television are also still here.

Ad c) A third type of theory consider the Internet/ digital media to be hegemonic media, which, in the words of Manuel Castells (1996-1998), establishes a new social morphology in the form of an Internet-supported 'space of flows' over top of all societies. Even if it might turn out not to be entirely false, it underestimates the role and function of the old media - which in turn are also digitized. In recent years, for instance, there are many indications that the old media have become significant - if not dominant - actors in the development of the Internet. I will provide two examples below.

\section{Hit is thue that all of the older media can be digitized, but this does not mean that this will ever happen, whether in the near future or in a "ong-term perspective."}

Ad d) Theories of convergence.The notion of converging media is widespread; unfortunately, it is very unclear (cf. Gordon 2003). Some of the former theories, foremost, complete replacement theory, can be considered as variants of convergence theory. Here, however, the notion is restricted to more limited versions:

d.1 One version is the idea of 'converging networks': the same networks will be used for telephone, television and Internet. This is already the case, though we also have a differentiation of networks (cable, satellite, and other forms of wireless networks: hotspots, community networks and cell phone wireless networks). More importantly, there is no relation between the technical convergence and the social functions and uses, except that broadband networks allow for even more differentiated forms of communication. The general principle for standardization in the ICT area is that standardization pertaining to lower semantic levels opens for differentiation on higher levels. Higher level standardization attempts, e.g. automatic translation programs, semantic web and a variety of high level artificial intelligence, fail or work only within a limited (closed) symbolic universe.

d. 2 A second version refers to mergers of the ICT, Telecom and Media corporations. One example is AOL/ Time-Warner, but it is unclear whether we have a unidirectional tendency, as we have also seen outsourcing 
processes and split-ups. Even more important: it is unclear that we will end up with parallel patterns and structures in different areas of the world. In a European context, one must consider the future role of public service institutions in this respect. For the Internet, one must also always consider the role of non-commercial, civil society activities.

d.3 A third group relates to the fact that news and other services are spread via all platforms, giving rise to

\section{Theories of supplementation are dominating in the established communication and (broad cast) media studies."}

the convergence of content, genres and services. Related to this is also the idea of the convergence of screens: that we will use the same screen for all sorts of communication. It is true that we have news on a variety of platforms, but we also witness a tendency to modify the formats and genres according to the specific properties (biases and affordances) of each platform, as well as different strategies for utilizing combinations of different media - such as using the Internet to establish a community related to a television program.

d. 4 Finally, there is a less theoretical but rather widespread idea of convergence as an adaptation of 'new media' to the standards of 'old' media, implying that "new media are not actually that new" (Schultz 2006). Here, the arguments given in the first section are applicable. If convergence is the front side of the coin, then there are a number of differentiation processes on the backside. The notion of convergence becomes overloaded. At the same time, it alludes to a predictable future, whereas the media world looks more like a universe of increasing complexity.

Ad e) Theories of supplementation are dominating in the established communication and (broad cast) media studies. The classification within a single group may be slightly unjustified, as there are different ideas about how the Internet and digital media supplement broadcast media. While Dahlgren (2001) argues that "the Internet does have a capacity to enhance the public sphere", Sparks (2001) notes that we are far from being close to establish something akin to a "global public sphere." The divergence between these positions relates to the question as to whether a public sphere can only exist within the singular, either within a nation state or as globalized sphere, or in the plural; and how a global public sphere relates to national public spheres. Dahlgren and Sparks appear to agree with most scholars in the field that the Internet is a medium for differentiated communication and incapable of functioning as a medium for a centralized political debate; neither on a national nor transnational scale.

Born (2006) argues that the Internet facilitates a series of communicative features of relevance for a renewed concept of public service based on a "politics for complex cultural dialogue." According to Born, "different media - broadcast, narrowcast, networked, and point-to-point - have the potential to fulfill different normative purposes," not least because "there is something of an elective affinity between digital media and the politics of difference." However, she also admits that the exploitation of digital media for pluralist ends must be supplemented by the continuation of comprehensive or 'universal' channels (p. 56-57), which would probably imply a continuation of the role of centralized public service media and no end of mediatization.

The question is not simply normative; it is also empirical. It may turn out that the interrelation between television and the Internet will also enter into a kind of coevolutionary dynamic, changing both the media systems and the public sphere in yet unforeseen ways. Interactive broadcast television may constitute a contradictio in adjectum, but there may also be a huge array of new combinations of interactivity and mass audiences possible. There are also indications that the media strategies of younger people differ from those of older people. At the same time, people appear to adapt to a model with radio in the morning, Internet in the daytime and primetime television followed by late evening Internet use. The theories mentioned are incapable of identifying a number of relevant issues and essential aspects. The arguments given point towards a need for a theory of coevolution of old and new media within a new, more complex set of media.

As a main ingredient in such a theory, we can recall an idea from the early 2oth century (Riepl 1913 and Schanze 2002) that new media do not replace old media; rather, it supplements it. It should then be added that the new media also contribute to a refunctionalization of the old media, possibly implying that they are 
used in new ways. The new medium and the first-ever features are not the only innovative aspects; the increase in complexity is also innovative, together with the refunctionalizations of the old media. With the help of these assumptions, it will become possible to specify a set of trajectories for future development and address a number of often overlooked issues.

Murdoch wants to capitalize on any sort of mediated social interactivity wherever it takes place:

There are a variety of possible relations between old and new media. In the case of digital media, such variations can be generated both on the side of the producers and users, including cases in which these positions are blurred or integrated into one another. This includes citizen's journalism as well as My space-communication.

The integration of digital media in culture is influenced by the existing media and media systems as well as the existing social actors. We should therefore expect that the media systems developing around the world and within the EU will also differ due to previously existing differences and cultural influences. This is further discussed in section 3 below.

\section{Coevolution: A few examples}

Coevolution may assume many forms, some of which are deliberately chosen as part of deliberate media strategies. The following examples reveal how the old media are still more dominant actors and/or content providers on the Internet. They are also instantiations of two different forms for coevolutionary developments.

In April 2005, media mogul Rupert Murdoch (2005) announced a new Internet strategy, arguing that he himself had grown up in a centralized news system, while his daughters would never experience a world without broadband access everywhere. "I am a digital immigrant," he claimed, "while they are digital natives." "We have to adapt to this," he told his American editors. And so he does. Half a year later he had bought My Space, a heavily trafficked American community for youngsters. Of course, this is indication that Murdoch wants to capitalize on any sort of mediated social interactivity wherever it takes place. He is unconcerned with the content. But his straw tegy goes further. In the spring of 2006, he also announced a new editorial principle: we must get closer to the people, he said. The strategy will therefore be to provide news on all media platforms:

"... information is carried via print, newspapers, magazines and books. It is carried on television, laptops, personal organisers, cell phones and, of course, the web. The media use all these platforms to give the public access to this waterfall of information. This is how public opinion is shaped. And we know how public opinion can make history." (Murdoch, 2006)

This is how Murdoch plans to utilize the potentials of networked digital media. ${ }^{4}$ In Murdoch's eyes, news on the Internet are now on par with mediated social communication. If there is traffic, there is Murdoch. The trace is defined in this reciprocal relationship between the old and new media. Well, Murdoch is not "The Evolution", and his strategies do not necessarily succeed; or if they do, they do not necessarily define the future. Regardless, the case can be regarded as an indication that there is a strong coevolutionary dynamic between the old and new media in the contemporary media system.

Google News 5 offers a second example. The service allows you to scan a huge amount of news services according to a set of standardized or personalized criteria. You may also define the number of headlines within each category. According to Google, the service is based on news from more than 4500 news sites in a variety of languages. You receive the news in typical Google manner: click on a headline and you get the full story on the website of the original source. There are limits as regards the degree of specialization, and you will get mismatches owing to homonymic words. You may even be afraid that Google has entered into some sort of cooperation on censorship with any kind of regime, e.g. the Chinese. Nevertheless, the company provides a new mechanism, both in respect to scale and selection, for the distribution and selection of news. In this case, the content is provided by the old media but delivered on their individual websites/online editions while Google provides you with the facilities for the selection and tailoring of the content across the entire range of providers and due to the indivi- 
dual priorities of users. Again, the interrelations between the old and new media define the development.

A third example is the role of public service institutions, commercial television and print media and their online editions. In a number of European countries, public service channels such as the BBC are in the lead in providing news and background information on the Internet, both in respect to the amount of quality information and in respect to new formats. They are significant actors on the Internet, while they are transforming themselves in the same process. Until recently, the Internet editions of print media were dominated by print media traditions (Lauff \& Wurff 2006). However, today there are signs that they are on the move further into the new digitized landscape, both in the use of digital features and in a wider sense, as former print media corporations are transforming themselves into cross-media corporations throughout Europe.

\section{Will the development and integration of the Internet-differ due to cultural and social settings."}

To sum up: 1) The Internet and digital media generally provide new features and facilities, and digital media contribute to a general shift in the overall media matrix. 2) They do so, though not by replacing the old media. What we have is a process of coevolution, including the development of a variety of new interrelations. 3) While old media are refunctionalized/repurposed, they are also influential actors in the development of Internet services. 4) One of the implications is that existing cultural and social processes - not least those inherited in existing media systems - may lead to the development of different forms for the integration and utilization of the Internet in different cultures.

\section{Digital divides or cultural diversities?}

We shall now turn to the third: Will the development and integration of the Internet differ due to cultural and social settings, for instance differences in the existing media systems? In their book Comparing Media Systems, Daniel Hallin and Paolo Mancini describe three different media systems in the second half of the 2oth century (well before the Internet): the American liberalist model, the North European democratic corporatist model and the South European polarized pluralist Model.

The North European model, they say, represents a blend of the American and South European models as characterized by what they refer to as three coexistences - the first component representing the American model and the second component the South European model: coexistence of commercial media \& media tied to political and civil groups" coexistence of journalistic professionalism and political parallelism; coexistence of liberal freedom of the press and strong state intervention in media regulation.

If the old media - as claimed in section 2 - are significant actors on the Net, then we ought to expect such differences manifested in the development and integration of the Internet. However, their main prediction for the future is that the North and South European models are declining, while there is a strong tendency towards homogenization around the 'triumphant' liberalist model..$^{6}$ In this case, we ought to expect the models to come closer to each other, also on the new Internet platform.

Even so, significant differences remain, e.g. in the organization and functioning of public broadcast systems and the concept of public service in Northern Europe. There seems to be no direct equivalent to this in the American model, while the Internet penetration in Southern Europe is remarkably lower than in the US and Northern Europe. Of course, this will be a major hindrance for the use of the Internet as a significant aspect of the national public sphere in these countries. On the other hand, we must ask whether these models should be revised due to the properties of the digital media and the effects on their integration in the overall system. Again, the answer is 'yes' - for the following reasons.

First, the new matrix is more complex and based on an 'intensified interaction' between print media, electronic media and digital media. Cross-media relations are fundamental.

Second, the Internet changes the rules of the game because - contrary to the old media - it is based on a functional symmetry between the communicative parts, even if the actual communication is not symmetrical, as is often the case. The Internet is consequently more open for civil society activities, and the development is based on the coexistence of commercial activities, civil society activities and possibly public service activities 
(Abbate, 2001; and others). If local communities play a major role in American civil society and the civil society in the Scandinavian countries is much more based on participation and membership in all sorts of asso-ciations, societies or clubs, then one might also expect such differences manifested on the Internet. Similarly, the lower Internet penetration in Southern Europe may be a result of differences in civil society such as differences between the urbanized educated middleclass and the population living in the famous 'remote' rural areas. Especially of relevance is the coexistence of commercial and non-commercial services: you can choose to pay for the news or get them for free! This is so because of civil society activities due to the existence of public service providers and because of new business models developed on a commercial basis.

Third, the systems described by $\mathrm{H} / \mathrm{M}$ were anchored within well-established national horizons. In a final section, they point to the emergence of transnational media corporations. However, the Internet, which they hardly mention, also contributes to changing the delimitations of public spaces and spheres. It does so in two respects: on the one hand, it allows for a new, individualized, specialized and professionalized use; and on the other hand, for globalized reach. In the terms of $H / M$, one might speak of a new kind of coexistence of individualization and globalization.

Fourth, the Internet allows users to select and combine due to their own needs: this also invites the fragmentation of public spaces for public communication. print media and broadcast media have sold themselves as whole packages - as company brands. This remains possible - and relevant, not least for the building of centralized public opinion, but there is also a tendency to select specific services for specific purposes, where traditional media are also met by service providers from other sorts of expert systems.

There is not simply a tendency to separate short news from other sorts of information, but also to separate news from other sources and means of opinionbuilding. Short news are also on the fly in mobile media, while other sorts of information and public discourse might continue to require stationary media. On the users or citizens side, it will be of relevance to see to which degree and by which media the public will continue to synchronize itself versus to which degree and in which matters it will prefer asynchronous and more individualized and specialized communication.

Following these arguments, it is possible to establish a set of trajectories in the evolution of the new matrix, which constitutes itself around the emerging digital media, with the Internet and mobile media as the most significant poles thus far. The general argument is that the Internet contributes to a shift in the overall media system in a number of respects, including: 1) The coexistence of paid and unpaid news (and other services and activities).

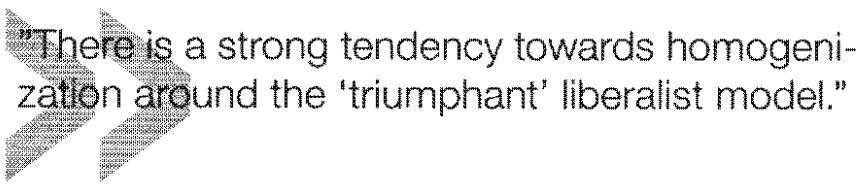

2) The coexistence of individualization and globalized reach. 3) The coexistence of a more complex system of public spaces fragmented according to specialized, professionalized and individualized needs and interests. 4) the coexistence of different media cultures, including different Internet cultures around the globe, not least in respect to the role of civil society. 5) The coevolution of media comprising intensified cross-media production and consumption as well as structural changes based on 24 hours per day availability of both synchronous and asynchronous mediated space.

The filling out of this new media matrix depends on the different social and cultural drivers, whether commercial or noncommercial - not least civil society and public service broadcast institutions, and their drive may lead to different developments concerning a variety of parameters for possible cultural variation, such as in the spread of and forms of hypertext, multimedia \& interactive communication as well as the utilizations of the spectrums a) private-public communication, b) local, national and transnational use, and c) differentiations according to personal and professional interest. 


\section{NOTES}

"For an elaborate analysis of the symbolic properties of the computer, see Finnemann (1997).

${ }^{2}$ The public formed around print media synchronized itself by reading periodicals (magazines, weeklies, and dailies), while the electronic mass media synchronized the audience (if not the entire way of life) via the program-slot structure. The regularities were always dependent on the available technology.

3 The notion of coevolution is borrowed from biology: "coevolution is a change in the genetic composition of one species (or group) in response to a genetic change in another. More generally, the idea of some reciprocal evolutionary change in interacting species is a strict definition of coevolution. At first glance (or thought), it might seem that everything is involved in coevolution. This assumption might stem from the fact that virtually all organisms interact with other organisms and presumably influence their evolution in some way ... Like the issue of defining an adaptation, we should not invoke coevolution without reasonable evidence that the traits in each species were a result of or evolved from the interaction between the two species."

Source: http://biomed.brown.edu/Courses/B1O48/27.Coevolution.HTML Accessed 10.4 2006.

"In the same speech, Murdoch declared himself to be a hardcore tech-determinist. History (or money?) is not made by politics, but by the dissemination of those waterfalls of information made possible by media.

5 news.google.com

This assessment builds both on journalistic and institutional criteria. The rise of transnational media corporations, the spread of information-oriented journalism separated from commentary, ideology, and personal opinions, and the development towards more independent media assuming their own position towards the political system - sometimes defined as the development of a secular 'media logic' (H\&M 2004: 253) and regarded as part of modern professionalization, specialization and commercialization. They are also pointing out a possible decline of the catchall media (as well as to other sorts of differentiation processes) due to a tendency towards more fragmented audiences (H\&M 2004: 286-287).

\section{REFERENCES}

Abbate, 1999, Mnenting the Internet, MIT Press, Cambridge, Mass.

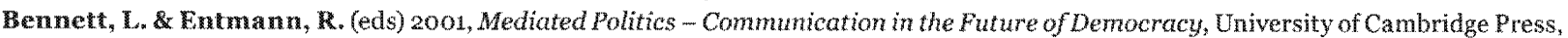
Cambridge.

Boltz, N. 1993, Am Ende der Gutenberg-Galaxis. die neuen Kommumikationsverhaltnisse, Fink Venlag, München.

Born, G, 2006, "Public Service Communications in the digital Era: Communicative Democracy, Pluxalism and the politics of Presence", in F. Colombo \& N. Vittadin, (eds.) Digitising TV. Theoretical Issues and Comparative Studies across Europe, Vita e Pensitro, Milano.

Castells, M. 1996-1998, The Information Age I-UT, Blackwell Publishing Ltd. London.

Castells, M. Himanen, . 2002, The Information Societyand the Welfare State, Oxford University press, Oxford.

Dallgrem, P. 2001, "The Public Sphere and the Net: Structure, Space, and Communication", in Bennet \& Entmann (eds), Mediated Politics - Communication in the Future of Democracy, University of Cambridge Press, Cambridge.

Debray, R. 1996 [1994], Media Manifestos, Verso, London. Translation of Manifestes médialogiques.

Deibert, R. 1997, Parchment, Printing, \& Hypermedia. Communication in World Order Thansformation, Columbia Univ. Press, New York. Finnemann, N.O. 1999, Modemity Modernised. The Culural mpact of Computerisation, in Mayer, P.A. (ed.) 1999, Computer Medias and Communication - A reader, Oxford University Press, Oxford.

Finneman, N.O. 2005. "The Cultural Grammar of the Internet, Jensen, K.B. (ed.) Tnterface//Cuhure - The World Wide Web as Political Resource and Aesthetic Form, Samfundsliteratur/Nordicom, Copenhagen.

Finnemann, N.O. forthcoming, "The Internet and the public Space", in Carlsson, U. (ed.) Nordic Media Trends, Nordicom, Goteborg.

Gordon, R. 2003, Convergence defined.

htp./www.ojrorg/ojr/business/1068686368.php. USC Annenberg, Online Journalism Review.

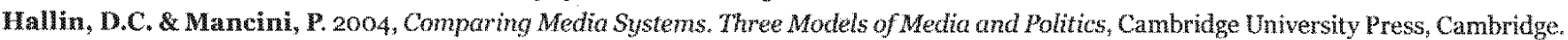
Levinsom, 1997. The Sof Edge. A Natural Wistory and Future of the Information Revolution, Routledge, London.

Mayer, P.A. (ed) 1999, Computer Medias and Communication-A reader, Oxford University Press, Oxford.

McLunan, M. (1964) 1994, Understanding Media-the Extensions of Man, MIT Press, Cambridge, MA.

Mitchell, W. (1995) 1996, City of Bits. Space, Place and he Infobahn, MIT Press, London.

Mitchell, W, 1999, E-topia Urban Life, Hm-but not as we know it, MIT Press, London.

Moravec, 1998, Simulation, Consciousness, Existence, http:/www.fre.ri.cmu.edu/ hpm/project.anchive/general.articles/1998/Sint 
ConEx.98.html (13.102003).

Moravec, H. 2000, Robots, Re-Evolving Mind, http:/www.frc.ri.cmu.edu/ hpm/project.archive/robot.papers/20oo/Cerebrum.html $(13.102003)$

Murdoch, R. 2005, Speech to the American Society of Newspaper Editors, http//www.newscorp.com/news/news_247.html (13.04 2005) Murdoch, R. 2006, Murdoch speech at Stationers Hall, http:/business, timesonline.co.uk/article/0,9071-2083911,00.html (14.3 2006). Negroponte, N. 1995, Being Digital, Alfred A. Knopf, Inc, New York.

Neumann, W.R. 2001, 'The impact of the New Media', in Bennett \& Entmann (eds.). , Mediated Politics - Communication in the Future of Democracy, University of Cambridge Press, Cambridge.

Nielsen, J. 1998, The End of Legacy Media. Alertbox.

http://www.useit.com/alertbox/980823.html (23.81998)

Poster, M. 1995, The Second Media Age, Polity Press, Cambridge.

Rheingold, H. 1993, The Virtual community, Addison Wesley, New York.

Riepl, M.W. 1913, 'Das Nachtrichten Wesen des Altertums mit besonderer Rücksicht auf die Römer' Leipzig. Schultz. Verlag

Sassen, S. 2006, 'Socio-Digital Formations. Constructing an Object of Study', Nordicom Information, vol. 28:2 2006. Nordicom, Göteborg. Schanze, H. (ed) 2002, Metzler Lexikon, Medietheorie, Medien Wissenschaft, Metzler Verlag, Stuttgart.

Schultz, W, 2004, 'Reconstructing Mediatization as an Analy tical Concept', European Journal of Communication, Sage Publications, vol. 19, no. 1, pp. $87-101$.

Sparks, C. 20o1, 'The Internet and the Global Public Sphere', in Bennett \& Entmann (eds.)., Mediated Politics - Commumication in the Future of Democracy, University of Cambridge press, Cambridge.

Wurf, R.v.d. \& Lauf, E. (eds) 2005 , Print and Online Newspapers in Europe. A Comparativee Analysis in 16 Countries. EU-COST a 20. Het Spinhuis, Amsterdam. 